\title{
Combination chemotherapy in advanced gastrointestinal cancers: ex vivo sensitivity to gemcitabine and mitomycin $C$
}

\author{
PA Whitehouse', SJ Mercer', LA Knight', F Di Nicolantonio', A O'Callaghan² and IA Cree, ${ }^{*, 1}$ on behalf of the \\ Portsmouth Upper GI and Colorectal Cancer Multidisciplinary Teams \\ 'Department of Histopathology, Translational Oncology Research Centre, Queen Alexandra Hospital, Portsmouth PO6 3LY, UK; ${ }^{2}$ Portsmouth Oncology \\ Centre, St Mary's Hospital, Portsmouth PO3 6AD, UK
}

\begin{abstract}
Advanced or metastatic disease is common in both oesophagogastric and colorectal cancers, with poor 5-year survival despite palliative chemotherapy. We have investigated the sensitivity of gastrointestinal tumours to gemcitabine in combination with mitomycin C (GeM), using a modified ex vivo ATP-based tumour chemosensitivity assay (ATP-TCA). Tumour material from 4 I colorectal and 22 oesophagogastric cancers were assessed. The GeM combination showed variable but definite activity in most of the samples tested. The results show that GeM achieves >95\% inhibition at concentrations within the range achievable clinically in $60 \%$ of colorectal tumours (2I out of 35) and 38\% of oesophagogastric tumours (five out of I 3 ) tested. We did not identify any significant difference in sensitivity using concurrent or sequential exposure of tumour-derived cells to these two drugs. The results from this study suggest that GeM may be a useful combination in the treatment of advanced gastrointestinal malignancy.

British Journal of Cancer (2003) 89, 2299-2304. doi:I0.I038/sj.bjc.660I403 www.bjcancer.com

(C) 2003 Cancer Research UK
\end{abstract}

Keywords: colorectal cancer; oesophageal cancer; gemcitabine; mitomycin C; chemotherapy; ATP-TCA

Colorectal adenocarcinoma (CRC) is the second most common cause of cancer death in the western world. Despite potentially curable surgical treatment in $70-80 \%$, half of all patients will die from metastatic disease, often within 5 years of diagnosis. Palliative chemotherapy may reduce the symptoms, extend survival from 6 to 12 months, and despite treatment-related adverse effects, often improve or at least maintain the quality of life (Nordic Gastrointestinal Tumour Adjuvant Therapy Group, 1992). In the UK, the current NICE guidance on chemotherapy in advanced colorectal disease (NICE, 2002) advocates the use of 5fluorouracil (5FU) with folinic acid (FA) as first line therapy. This combination achieves response rates of $18-22 \%$ and overall survivals of 12-15 months (de Gramont et al, 2000; Maiello et al, 2000). Combinations using newer agents such as irinotecan and oxaliplatin achieve higher response rates of up to $50 \%$ and longer median overall survivals (Douillard et al, 2000; Saltz et al, 2000; Grothey et al, 2002). However, the newer agents, especially in combination with 5FU/FA, are associated with greater toxicity, which may be severe and dose-limiting.

Oesophageal and gastric cancers together account for $7 \%$ of all cancer-related deaths. Palliative treatment may be achieved with chemotherapy, radiotherapy or chemoradiation. A number of chemotherapy regimens are in use. Most are triple therapies incorporating $5 \mathrm{FU}$ and cisplatin with either epirubicin or paclitaxel. Response rates of $48-70 \%$ have been achieved (Kim et al, 1993; Ilson et al, 1998) with a 2-year survival of $13.5 \%$ (Findlay et al, 1994); however, in general, the responses are often

* Correspondence: IA Cree; E-mail: ian.cree @port.ac.uk

Received 17 March 2003; revised 12 September 2003; accepted 22 September 2003 short lived and these treatments are associated with varying degrees of toxicity.

Recently, we investigated the chemosensitivity of colorectal and oesophagogastric adenocarcinomas (Mercer et al, 2003; Whitehouse et al, 2003) using a modified ex vivo ATP-based tumour chemosensitivity assay (ATP-TCA) (Andreotti et al, 1995; Cree et al, 1996). We demonstrated considerable differences in sensitivity between individual tumours of both tumour types. Mitomycin C (MMC) has been used in the treatment of gastrointestinal tumours for many years, although it is not now the most commonly used drug due to serious pulmonary, renal and haematological toxicities, which tend to occur with overdosage. It remains useful in the treatment of metastatic gastrointestinal tumours, usually in combination with 5-FA. Gemcitabine is licensed for use in pancreatic and non-small-cell lung cancers. It has also shown preclinical and clinical activity in several other solid tumours, including ovarian, head and neck and breast cancers (Carmichael et al, 1995; Markman, 2002). However, phase I/II trials of single-agent gemcitabine have not demonstrated any activity in advanced colorectal and gastric cancers (Moore et al, 1992; Christman et al, 1994; Mani et al, 1998). We therefore wished to test this combination on further gastrointestinal tumour samples and investigate any schedule dependency.

\section{MATERIALS AND METHODS}

\section{Tumours}

Material from 41 colorectal and 22 oesophagogastric tumours was tested. All the colorectal tumours were previously untreated. Six of the oesophagogastric tumours had received neoadjuvant 
chemotherapy with epirubicin + cisplatin +5-FA (ECF). The median age of patients undergoing colorectal resection was 70 years (range 39-86) and for oesophagogastric resection was 69 years (range 39-87). The local ethics committee approval for the use of tissue or cells not required for diagnosis was obtained, and informed consent gained from all patients.

\section{ATP-tumour chemosensitivity assay}

The ATP-tumour chemosensitivity assay (ATP-TCA) was performed as previously described (Andreotti et al, 1995; Cree, 1998). Tumour samples were transported to the laboratory in transport medium consisting of Dulbecco's modified Eagle's medium (Sigma, Poole, UK; D5671), minced and dissociated overnight in collagenase (Sigma; C8051). The concentration of collagenase used was $0.75 \mathrm{mg} \mathrm{ml}^{-1}$ for oesophagogastric samples and $1.5 \mathrm{mg} \mathrm{ml}^{-1}$ for colorectal samples. If necessary, the samples were purified using Ficoll-hypaque density centrifugation (Sigma; 1077-1) to remove red blood cells and cell debris. The remaining cells were resuspended in antibiotic containing serum-free complete assay medium (CAM) (DCS Innovative Diagnostik Systeme, Hamburg, Germany) at $200000 \mathrm{cells} \mathrm{ml}^{-1}$. Additional amphotericin B $\left(2.5 \mu \mathrm{g} \mathrm{ml}^{-1}\right)$ was added to the CAM for the oesophagogastric samples, and amphotericin B $\left(2.5 \mu \mathrm{g} \mathrm{ml}^{-1}\right)$ and metronidazole $\left(1 \mu \mathrm{g} \mathrm{ml}^{-1}\right)$ were added to the CAM for the colorectal samples, as previously described (Whitehouse et al, 2003). 96-well polypropylene plates (Corning-Costar, High Wycombe, UK) were prepared with $100 \mu \mathrm{l}$ of CAM, to which the drugs were added at six concentrations in triplicate. Two internal controls were included in each plate: a maximum inhibitor (MI) that kills all the cells resulting in a zero ATP count, and a medium only (MO) without any drugs. After 6 days incubation at $37^{\circ} \mathrm{C}$ with $5 \% \mathrm{CO}_{2}$, the cells were lysed with a detergent-based tumour cell extraction reagent (DCS Innovative Diagnostik Systeme). A volume of $50 \mu \mathrm{l}$ from each well was transferred to the wells of a 96-well white plate (Thermo Life Sciences, Basingstoke, UK), to which $50 \mu \mathrm{l}$ of luciferinluciferase counting reagent (DCS Innovative Diagnostik Systeme) was added. The ATP content of each well was quantified by the amount of light produced in a microplate luminometer (Bethold MPLX). The results are expressed as the percent inhibition achieved at each concentration tested, calculated as: \% inhibition $=1-($ test $-\mathrm{MI}) /(\mathrm{MO}-\mathrm{MI}) \times 100$.

\section{Drugs}

Mitomycin C (Kyowa, London, UK) and Gemcitabine (Eli Lilly, Basingstoke, UK) were obtained as vials for injection, and made up according to the manufacturer's instructions. Both MMC and gemcitabine were stored as aliquots at $-20^{\circ} \mathrm{C}$ (Hunter et al, 1994). The $100 \%$ test drug concentrations (TDCs) used were calculated from pharmacokinetic data to approximate concentrations clinically achievable in the patient (Andreotti et al, 1995). While this has inevitable inaccuracies, the $100 \%$ TDC of MMC was $0.7 \mu \mathrm{g} \mathrm{ml}^{-1}$ $(2.0 \mu \mathrm{m})$ and the $100 \%$ TDC of gemcitabine was $12.5 \mu \mathrm{g} \mathrm{ml}^{-1}$ $(40 \mu \mathrm{M})$. Drug dilutions were prepared in the plates from freshly made up $800 \%$ TDC drug solutions. Combinations of drugs were made by adding both drugs, each at its $800 \%$ TDC. In combinations tested in the assay, drugs are present at decreasing concentrations in a constant ratio.

Sequential studies were performed by testing (i) MMC and gemcitabine, both added at $0 \mathrm{~h}$; (ii) $\mathrm{MMC}$ at $0 \mathrm{~h}$ followed by the addition of gemcitabine at $6 \mathrm{~h}$; (iii) $\mathrm{MMC}$ at $0 \mathrm{~h}$ and gemcitabine at $24 \mathrm{~h}$; and (iv) gemcitabine at $0 \mathrm{~h}$ with MMC added at $24 \mathrm{~h}$.

\section{Data analysis}

Data from each assay were transferred directly from the luminometer to an Excel 2000 spreadsheet (Microsoft). A number of indices of efficacy can be calculated from the data, including the $\mathrm{IC}_{90}$. The natural logarithmic sum index (Index $\mathrm{SUM}_{\mathrm{S}}$ ), calculated by summing the percentage inhibition at each concentration, has been found to allow the best comparison of responses between samples (Hunter et al, 1993). In addition, the area under the concentration-inhibition curve (Index $\mathrm{AUC}_{\mathrm{AC}}$ ) and the percentage of tumours achieving 95\% inhibition have been calculated. Combination effects were assessed using the method established by Poch et al (1995), as previously used with the ATP-TCA (Kurbacher et al, 1997). This is used in preference to the Chou and Talalay method, because it is better able to deal with drugs which produce a shallow dose-response curve (Chou and Talalay, 1984). However, we have also performed a Chou and Talalay analysis, where the combination index (CI) was determined at $90 \%$ cell death, and was defined as follows:

$$
\begin{aligned}
\mathrm{CI}_{\mathrm{A}+\mathrm{B}}= & {\left[\left(\mathrm{D}_{\mathrm{A} / \mathrm{A}+\mathrm{B}}\right) / \mathrm{D}_{\mathrm{A}}\right]+\left[\left(\mathrm{D}_{\mathrm{B} / \mathrm{A}+\mathrm{B}}\right) / \mathrm{D}_{\mathrm{B}}\right] } \\
& +\left[\operatorname{alpha}\left(\mathrm{D}_{\mathrm{A} / \mathrm{A}+\mathrm{B}} \times \mathrm{D}_{\mathrm{B} / \mathrm{A}+\mathrm{B}}\right) / \mathrm{D}_{\mathrm{A}} \mathrm{D}_{\mathrm{B}}\right]
\end{aligned}
$$

where $\mathrm{CI}_{\mathrm{A}+\mathrm{B}}=\mathrm{CI}$ for a fixed effect $(\mathrm{F}=90 \%)$ for the combination of cytotoxic $\mathrm{A}$ and cytotoxic $\mathrm{B} ; D_{\mathrm{A} / \mathrm{A}+\mathrm{B}}=$ concentration of cytotoxic $\mathrm{A}$ in the combination $\mathrm{A}+\mathrm{B}$, giving an effect $\mathrm{F} ; D_{\mathrm{B} /}$ $\mathrm{A}+\mathrm{B}=$ concentration of cytotoxic $\mathrm{B}$ in the combination $\mathrm{A}+\mathrm{B}$, giving an effect $\mathrm{F} ; D_{\mathrm{A}}=$ concentration of cytotoxic $\mathrm{A}$ alone, giving an effect $\mathrm{F} ; D_{\mathrm{B}}=$ concentration of cytotoxic $\mathrm{B}$ alone, giving an effect $F$. alpha $=$ parameter with value 0 when $A$ and $B$ are mutually exclusive, and 1 when $A$ and $B$ are mutually nonexclusive.

The combination index indicated: synergism $<0.8$; additivity $>0.8$ and $<1.2$; antagonism $<1.2$; slight synergistic and additive cytotoxic activity for values of 0.8 and 1.2, respectively.

\section{RESULTS}

Evaluable results were obtained from 60 out of 63 tumours, giving an evaluability rate of $95 \%$. Three tumours were not evaluable due to contamination of the cell culture. Despite the addition of extra antibiotics during specimen preparation, contamination is a problem with such tissue and these samples are technically challenging (Whitehouse et al, 2003).

The single-agent results are shown in Figure 1 and Table 1. There is considerable heterogeneity between tumours for these two drugs, with sensitivity to MMC in $71 \%$ of the oesophagogastric tumours (15 out of 21$)$ and $59 \%$ of the colorectal tumours (21 out of 39). For comparison between drugs and tumours, an Index $\mathrm{X}_{\mathrm{SUM}}$ of $<300$, representing an average $50 \%$ inhibition across all concentrations tested, has been used to indicate sensitivity, as previously published (Hunter et al, 1993; Cree et al, 1999). Despite these apparently encouraging results, MMC alone achieves $>95 \%$ inhibition at clinically achievable concentrations in just $14 \%$ of oesophagogastric tumours (three out of 21 ) and $10 \%$ of colorectal tumours (four out of 39) tested. Gemcitabine alone is active on the basis of an IndexSUM $<300$ in $42 \%$ of oesophagogastric tumours and $50 \%$ of colorectal tumours. However, it tends to have a very shallow dose-response curve and only rarely produced $>95 \%$ inhibition at clinically achievable concentrations: $6 \%$ of oesophagogastric tumours (one out of 17) and $3 \%$ of colorectal tumours (one out of 38).

In contrast to the single-agent results, gemcitabine in combination with MMC (GeM) achieves $>95 \%$ inhibition at clinically achievable concentrations in $60 \%$ of colorectal tumours (21 out of 35 ) and $38 \%$ of oesophagogastric tumours (five out of 13) tested (Table 1). The use of an Index $\mathrm{SUM}_{\mathrm{S}}<300$ threshold for combinations tends to overstate the sensitivity, and it is not surprising that $100 \%$ of the tumours tested reached this threshold for sensitivity, as applied to single agents. Even when the Index $\mathrm{SUM}_{\mathrm{M}}$ is decreased to $<200$, GeM is active in 100 and $89 \%$ of oesophagogastric and colorectal tumours, respectively. Figure 1 shows this as a shift in 
activity towards the lower concentrations tested. In oesophageal tumours, the addition of gemcitabine decreased the MMC $\mathrm{IC}_{90}$ from 3.89 to $0.86 \mu \mathrm{M}$, and for colorectal tumours the $\mathrm{MMC} \mathrm{IC}_{90}$ was decreased from 3.73 to $0.96 \mu \mathrm{M}$. Using the Chou and Talalay method, this equates for oesophageal cancers to a CI90 of 0.41 (synergism) and for colorectal cancers to a CI90 of 0.44 (synergism).

The CRC example shown in Figure 2A shows the advantage of the GeM combination over the individual agents in terms of inhibition. When analysed by the method of Poch et al (1995), by which the observed effect at each concentration tested is compared with that expected, the effect is greater than additive (Figure 2B).
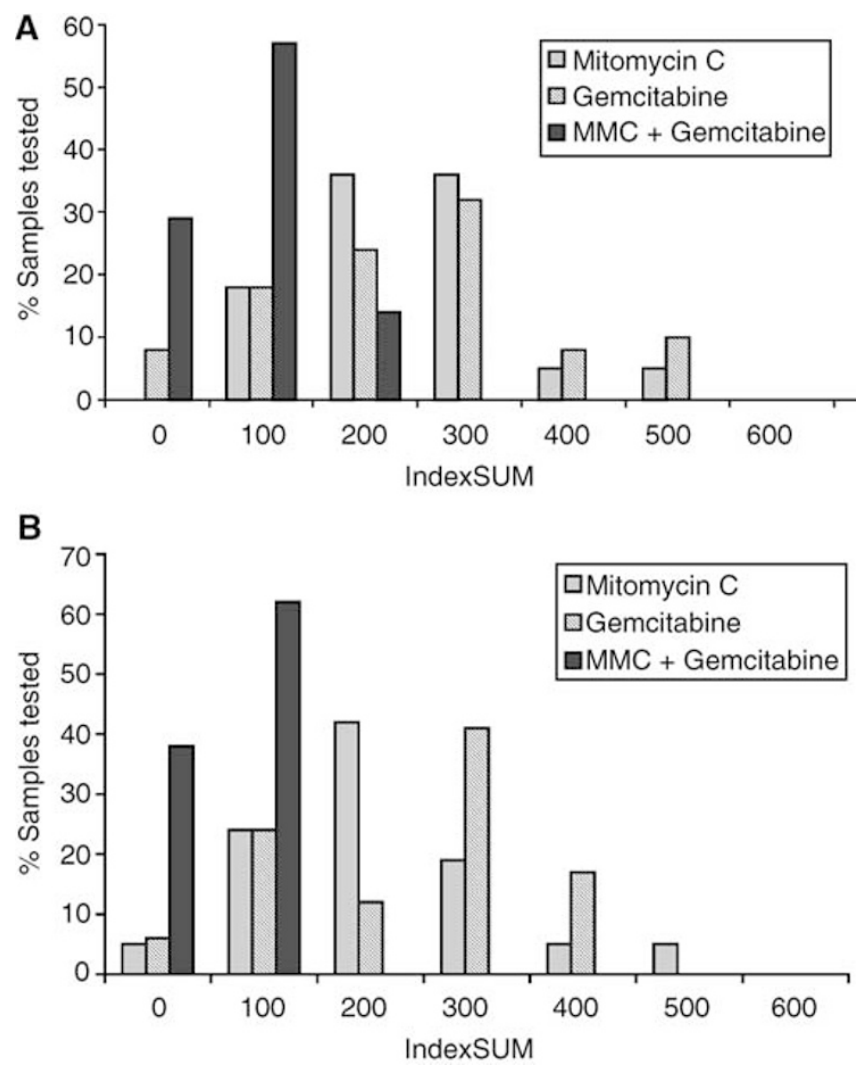

Figure I Summary of the heterogeneity of activity in the ATP-TCA to $M M C$, gemcitabine, and the combination $(\mathrm{GeM})$ in $(\mathbf{A})$ colorectal cancer $(n=39)$, and $(\mathbf{B})$ oesophagogastric cancer $(n=21)$. The IndexSUM is a parameter describing the concentration-inhibition curve for each drug, or combination in a single number. Using the IndexSUM $<300$ to indicate sensitivity, GeM is clearly more active than either single agent.
Schedule experiments of gemcitabine and MMC are shown in Figure 3. These experiments were performed, in at least triplicate, by adding $6.25-200 \%$ TDC of gemcitabine to $6.25-200 \%$ TDC of MMC at 0,6 and $24 \mathrm{~h}$. Mitomycin $\mathrm{C}$ was also added to gemcitabine at $24 \mathrm{~h}$. There was no apparent difference in inhibition between the
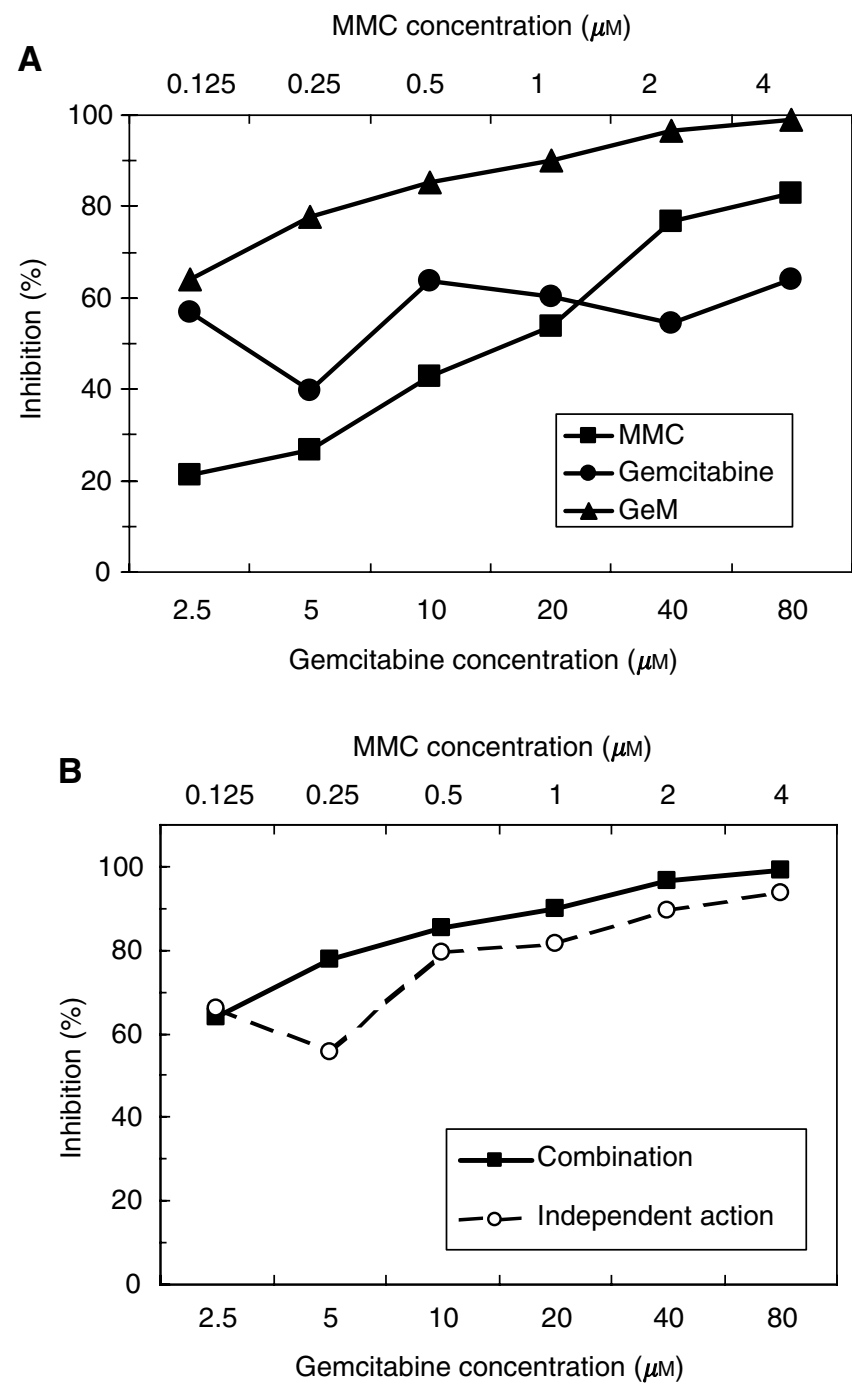

Figure 2 (A) Inhibition-concentration curve in a colorectal tumour sample. (B) By the method of Poch et al. (1995), the observed effect of the combination at each concentration is greater than the expected effect (independent action).

Table I Summary of sensitivity data (using an arbitrary threshold of sensitivity defined as a IndexSUM $<300$ for six concentrations used)

\begin{tabular}{lcccc}
\hline Drug & No. assessed & No. sensitive & $\begin{array}{c}\text { Sensitivity (\%) } \\
\text { (Index }<\mathbf{3 0 0 )}\end{array}$ & $\mathbf{> 9 5 \% \text { Inhibition (\%) }}$ \\
\hline $\begin{array}{l}\text { Oesophagogastric cancer } \\
\text { Mitomycin C }\end{array}$ & 21 & 15 & 71 & 14 (three out of 21) \\
$\quad \begin{array}{l}\text { Gemcitabine } \\
\text { Mitomycin C+Gemcitabine }\end{array}$ & 17 & 7 & 42 & 6 (one out of 17) \\
Colorectal cancer & 13 & 13 & 100 & 38 (five out of 13) \\
Mitomycin C & & & & \\
Gemcitabine & 39 & 21 & 54 & 10 (four out of 39) \\
Mitomycin C+gemcitabine & 38 & 19 & 50 & 3 (one out of 38) \\
\hline
\end{tabular}




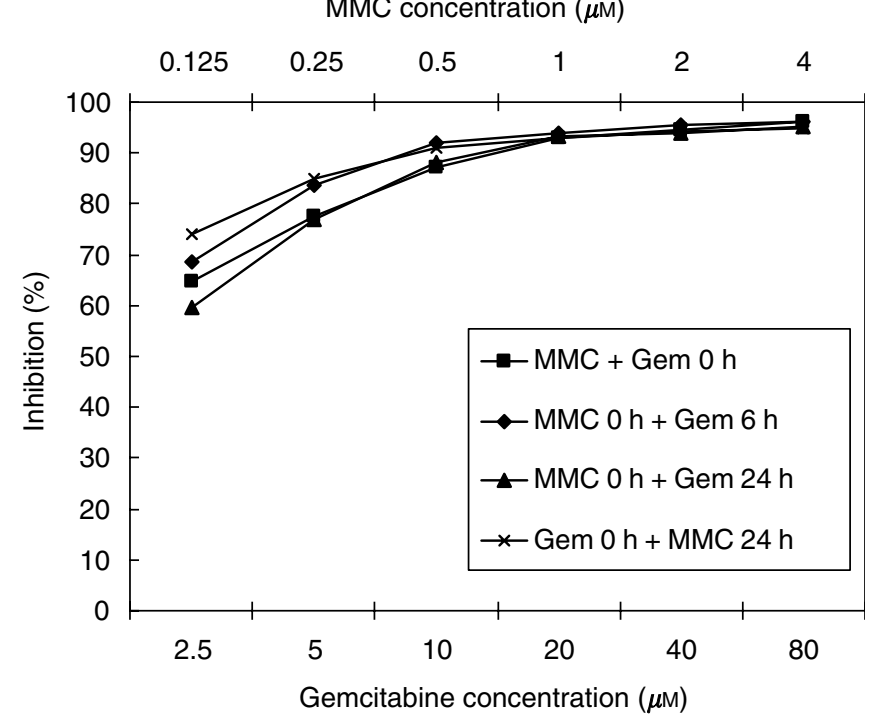

Figure 3 Schedule studies of gemcitabine in combination with MMC. No schedule dependency has been demonstrated.

different schedules (93.84-95.84\% tumour growth inhibition at $100 \%$ TDC), although gemcitabine added to MMC at $24 \mathrm{~h}$ did produce the lowest growth inhibition of $93.84 \%$ ).

\section{DISCUSSION}

These results show that, ex vivo, the combination of gemcitabine and MMC (GeM) is more effective than the single agents alone, when tested on gastrointestinal tumours. Our previous studies have shown this to be the most active combination in the assay, when tested alongside standard treatment regimens (Mercer et al, 2003; Whitehouse et al, 2003), with 38\% of oesophagogastric tumours and $60 \%$ of colorectal tumours tested, showing $>95 \%$ inhibition in the ex vivo ATP-TCA. We believe the $95 \%$ inhibition figure to be important, as this is the level of tumour cell kill required for most logarithmic kill models to show effects (Goldie and Coldman, 1979). While these data may not of course translate into clinical efficacy of similar magnitude, it does provide a basis for the clinical investigation of this combination in gastrointestinal tumours. The difference in sensitivity between the two tumours may be related to tumour type, to the proportion of previously treated oesophageal cancer samples included in the study, or to the necessary inclusion of metronidazole in the cell cultures from colorectal tumours. In a previous study (Whitehouse et al, 2003), we tested the antibiotics at varying concentrations in combination with chemotherapeutic agents against cell lines and tumour samples, and were unable to show any additional toxicity at the concentrations used in this study. We believe that the effect of previous treatment may be a major factor in this unexpected difference between these two tumour types.

Mitomycin $\mathrm{C}$ has been used in the treatment of gastrointestinal malignancies for over 30 years, and has been shown to be relatively safe and effective (Chester et al, 2000), although very rarely patients may develop the haemolytic-uraemic syndrome, usually at very high doses (Catalano et al, 2002; Gundappa et al, 2002). Pulmonary and renal toxicities are also a problem in some patients, again usually at high cumulative doses. It is a DNAdamaging drug, inhibiting DNA synthesis by crosslinking adenosine and guanine under anaerobic conditions (Spanswick et al, 1998). Single-agent MMC has produced response rates of up to $23 \%$ in colorectal cancer (Moertel et al, 1968; Moore et al, 1968).
The combination of MMC and 5FU has shown synergistic growth inhibition of cell lines (Sartorelli and Booth, 1965), including colorectal cancer cell lines (Russello et al, 1989). A randomised controlled trial in colorectal cancer found that MMC in combination with protracted venous infusion (PVI) 5FU increased the response rates to $54 \%$, but with no benefit to overall and 1-year survival (Ross et al, 1997). A further phase III study confirmed an improved response rate with a survival benefit at 2 years (Price et al, 1999). Mitomycin C has been used in combination therapy of oesophagogastric cancers. Although initial response rates of $40 \%$ were quoted for treatment with FAM (5FU, doxorubicin and MMC) (MacDonald et al, 1979), no benefit has been demonstrated from the addition of MMC to 5FU (Tebbutt et al, 2002). MCF (MMC, cisplatin and 5FU) has no survival advantages over standard treatment with ECF (epirubicin, cisplatin, 5FU) (Ross et al, 2002).

Gemcitabine is an antimetabolite cytidine analogue with a number of mechanisms of cytotoxicity. Intracellular phosphorylation to its active metabolite results in (a) prevention of DNA synthesis by inhibiting DNA polymerases and by competing with deoxycytidine triphosphate, (b) inhibition of ribonucleotide reductase, depleting deoxynucleotide pools and favouring incorporation of gemcitabine into DNA, (c) incorporation into DNA, decreasing the accuracy of DNA replication and repair, and (d) incorporation into RNA. It should be noted that the effect of gemcitabine on ribonucleotide reductase could affect ATP levels, possibly as part of its cytostatic effect, though gemcitabine is inactive against many solid tumours (Neale et al, 1999) and this does not seem to be a problem for its use in the assay.

Gemcitabine, which is cell cycle specific, and well tolerated clinically, is an attractive drug for use in combination with DNAdamaging agents (Huang et al, 1991); particularly it has been shown to modulate the activity of a wide range of DNA-damaging agents, including platinum (Peters et al, 1995; Sandler et al, 2000) and alkylating agents (Neale et al, 1999). We have not investigated the exact mechanism of modulation of MMC sensitivity with gemcitabine, but this may be due to inhibition of repair of alkylating agent-induced DNA adducts, an increase in DNA double-strand breaks or changes in dNTP pools. Studies of gemcitabine in combination with cisplatin are based on this mechanism of action (Cardenal et al, 1999). This study raises the question as to whether other alkylating agents might be effective in combination with gemcitabine in gastrointestinal cancer.

There are very few in vitro studies of gemcitabine and MMC. The combination was found to be synergistic after $4 \mathrm{~h}$ on a Lewis lung cancer cell line, without any increase in DNA double-strand breaks (van Moorsel et al, 1997). Similarly, MMC and gemcitabine had a synergistic effect, when administered concurrently, but not sequentially, on the HT29 human colon cancer cell line (Aung et al, 2000), suggesting that gemcitabine could be beneficial in the treatment of cancers sensitive to MMC.

Clinical studies are also few in number: intravenous and intraarterial locoregional treatment with MMC and gemcitabine has been found to be highly effective with improved response rates in pancreatic cancer (Klapdor et al, 2000). This drug combination (median total dose MMC $32 \mathrm{mg} \mathrm{m}^{-2}$ ) has been administered together with radiotherapy with tolerable toxicity (Korneck et al, 2001).

In this study, we have not demonstrated any schedule-specific alterations in chemosensitivity; there were no protective effects on the cells of prior addition of gemcitabine as we have previously reported for treosulfan + gemcitabine (Neale et al, 1999). It should be noted that the nature of the assay means that, in all experiments, the cells were exposed to the combination for at least 5 days. However, a study of MMC and gemcitabine on the HT29 human colon cancer cell line showed simultaneous exposure to be necessary to demonstrate synergism (Aung et al, 2000). The effect of gemcitabine in combination with other alkylating and platinum agents has also been shown to be time-dependent 
(Braakhuis et al, 1995; Neale et al, 1999; van Moorsel et al, 2000). Since simultaneous administration is generally preferable to patients and oncology units, it would probably be reasonable to give both drugs together in future clinical studies.

These results demonstrate that gemcitabine + MMC $(\mathrm{GeM})$ is effective ex vivo against tumour-derived cells from both oesophageal and CRCs. There is little evidence of schedule dependency and simultaneous administration should be feasible. These results have encouraged us to explore the GeM regimen further in a phase I/II

\section{REFERENCES}

Andreotti PE, Cree IA, Kurbacher CM, Hartmann DM, Linder D, Harel G, Gleiberman I, Caruso PA, Ricks SH, Untch M, Sartori C, Bruckner HW (1995) Chemosensitivity testing of human tumors using a microplate adenosine triphosphate luminescence assay: clinical correlation for cisplatin resistance of ovarian carcinoma. Cancer Res 55: 5276-5282

Aung TT, Davis MA, Ensiminger WD, Lawrence TS (2000) Interaction between gemcitabine and mitomycin-C in vitro. Cancer Chemother Pharmacol 45: $38-42$

Braakhuis BJ, Ruiz van Haperen VW, Welters MJ, Peters GJ (1995) Schedule-dependent therapeutic efficacy of the combination of gemcitabine and cisplatin in head and neck cancer xenografts. Eur $J$ Cancer 31A: $2335-2340$

Cardenal F, Lopez-Cabrerizo MP, Anton A, Alberola V, Massuti B, Carrato A, Barneto I, Lomas M, Garcia M, Lianes P, Montalar J, Vadell C, Gonzalez-Larriba JL, Nguyen B, Artal A, Rosell R (1999) Randomized phase III study of gemcitabine-cisplatin versus etoposide-cisplatin in the treatment of locally advanced or metastatic non-small-cell lung cancer. $J$ Clin Oncol 17(1): $12-18$

Carmichael J, Possinger K, Phillip P, Beykirch M, Kerr H, Walling J, Harris AL (1995) Advanced breast cancer: a phase II trial with gemcitabine. $J$ Clin Oncol 13(11): $2731-2736$

Catalano C, Gianesini C, Fabbian F (2002) Erthyropoietin is beneficial in mitomycin-induced haemolytic-uremic syndrome. Nephron 91(2): $324-326$

Chester JD, Dent JT, Wilson G, Ride E, Seymour MT (2000) Protracted infusional 5-fluorouracil (5-FU) with bolus mitomycin in 5-FU-resistant colorectal cancer. Ann Oncol 11: 235-237

Chou TC, Talalay P (1984) Quantitative analysis of dose-effect relationships: the combined effects of multiple drugs or enzyme inhibitors. $A d v$ Enzyme Regul 22: 27-55

Christman K, Kelson D, Saltz L, Tarassoff PG (1994) Phase I trial of gemcitabine in patients with advanced gastric cancer. Cancer 73: 5-7

Cree IA (1998) Luminescence-based cell viability testing. In Bioluminescence Methods and Protocols, Methods in Molecular Biology Vol 102. LaRossa RA (ed) pp 169-177. Clifton, UK: Humana Press

Cree IA, Kurbacher CM, Untch M, Sutherland LA, Hunter EMM, Subedi AMC, James EA, Dewar JA, Preece PE, Andreotti PE, Bruckner HW (1996) Correlation of the clinical response to chemotherapy in breast cancer with ex vivo chemosensitivity. Anti-Cancer Drugs 7: 630-635

Cree IA, Neale MH, Myatt NE, de Takats PG, Hall P, Grant J, Kurbacher CM, Reinhold U, Neuber K, MacKie RM, Chana J, Weaver PC, Khoury GG, Sartori C, Andreotti PE (1999) Heterogeneity of chemosensitivity of metastatic cutaneous melanoma. Anti-Cancer Drugs 10: 437-444

de Gramont A, Figer A, Seymour M, Homerin M, Hmissi A, Cassidy J, Boni C, Cortes Funes H, Cervantes A, Freyer G, Papamichael D, Le Bail N, Louvet C, Hendler D, de Braud F, Wilson C, Morvan F, Bonetti A (2000) Leucovorin and fluorouracil with or without oxaliplatin as first-line treatment in advanced colorectal cancer. J Clin Oncol 18: $2938-2947$

Douillard JY, Cunningham D, Roth AD, Navarro M, James RD, Karasek P, Jandik P, Iveson T, Carmichael J, Alakl M, Gruia G, Awad L, Rougier P (2000) Irinotecan combined with fluorouracil compared with fluorouracil alone as first line treatment for metastatic colorectal cancer. A multicentre randomised trial. Lancet 355: $1041-1047$

Findlay M, Cunningham D, Norman A, Mansi J, Nicolson M, Hickish T, Nicolson V, Nash A, Sacks N, Ford H, Carter R, Hill A (1994) A phase II study in advanced gastro-oesophageal cancer using epirubicin and cisplatin in combination with continuous infusion 5-fluorouracil (ECF). Ann Oncol 5: 609-616 clinical trial to establish its safety and efficacy in metastatic gastrointestinal cancer.

\section{ACKNOWLEDGEMENTS}

This project was partly funded by the European Commission (grant number BMH4-CT98-9522). Surg Lt Cdr Mercer RN is funded by the Royal Navy.
Goldie JH, Coldman AJ (1979) A mathematical model for relating the drug sensitivity of tumours to their spontaneous mutation rate. Cancer Treat Rep 63(11-12): $1727-1733$

Grothey A, Deschler B, Kroening H, Ridwelski K, Reichardt P, Kretzschmar A, Clemens M, Hirschmann W, Lorenz M, Asperger W, Buechele T, Schmoll H-J (2002) Phase III study of bolus 5-fluorouracil (5-FU)/folinic acid (FA) (mayo) vs weekly high-dose 24h 5-FU infusion/FA + oxaliplatin (OXA) (FUFOX) in advanced colorectal cancer (ACRC). Proc ASCO 512 (abstract)

Gundappa RK, Sud K, Kohli HS, Gupta KL, Joshi K, Sakhuja V (2002) Mitomycin-C induced haemolytic uremic syndrome: a case report. Ren Fail 24(3): 373-377

Huang P, Chubb S, Hertel LW, Grindey GB, Plunkett W (1991) Action of $2^{\prime}, 2^{\prime}$-difluoro-deoxycytidine on DNA synthesis. Cancer Res 51: 6110-6117

Hunter EM, Sutherland LA, Cree IA, Dewar JA, Preece PE, Andreotti PE (1993) Heterogeneity of chemosensitivity in human breast carcinoma: use of an adenosine triphosphate (ATP) chemiluminescence assay. Eur J Surg Oncol 19: 242-249

Hunter EM, Sutherland LA, Cree IA, Subedi AMC, Hartmann D, Andreotti PE (1994) The influence of storage on cytotoxic drug activity in an ATPbased chemosensitivity assay. Anti-Cancer Drugs 5: 171-176

Ilson DH, Ajani J, Bhalla K, Forastiere A, Huang Y, Patel P, Martin L, Donegan J, Pazdur R, Reed C, Kelsen DP (1998) Phase II trial of paclitaxel, fluorouracil, and cisplatin in patients with advanced carcinoma of the esophagus. J Clin Oncol 16(5): 1826-1834

Kim NK, Park YS, Heo DS, Suh C, Kim SY, Park KC, Kang YK, Shin DB, Kim HT, Kim HJ, Kang WK, Suh CI, Bang YJ (1993) A phase III randomised study of 5-fluouracil and and cisplatin versus 5-fluouracil, doxorubicin and mitomycin $\mathrm{C}$ versus 5 -fluorouracil alone in the treatment of advanced gastric cancer. Cancer 71: 3813-3818

Klapdor R, Muller C, Seutter R, Bahlo M, Peters W, Fenner C (2000) Improvement of survival by efficacy orientated polychemotherapy of exocrine pancreatic cancer. Anticancer Res 20: 5201 - 5207

Korneck GV, Potter R, Selzer E, Schratter A, Ulrich-Pur H, Rogy M, Kraus G, Scheithauer W (2001) Combined radiochemotherapy of locally advanced unresectable pancreatic adenocarcinoma with mitomycin $\mathrm{C}$ plus 24-hour continuous infusional gemcitabine. Int J Radiat Oncol Biol Phys 49: $665-671$

Kurbacher CM, Bruckner HW, Cree IA, Kurbacher JA, Wilhelm L, Poch G, Indefrei D, Mallmann P, Andreotti PE (1997) Mitoxantrone combined with paclitaxel as salvage therapy for platinum-refractory ovarian cancer: laboratory study and clinical pilot trial. Clin Cancer Res 3: 1527-1533

MacDonald JS, Woolley PV, Smythe T, Ueno W, Hoth D, Schein PS (1979) 5fluorouracil, adriamycin and mitomycin C (FAM) combination chemotherapy in the treatment of advanced gastric cancer. Cancer 44: 42-47

Maiello E, Gebbia V, Giuliani F, Paoletti G, Gebbia N, Cigolari S, Fortunato S, Pedicini T, Borsellino N, Lopez M, Colucci G (2000) 5-flurouracil and folinic acid with or without CPT-11 in advanced colorectal cancer patients: a multicentre randomised phase II study of the Southern Italy Oncology Group. Ann Oncol 11: 1045-1051

Mani S, Kugler JW, Knost JA, Sciortino DF, Gibbons J, Garcia JC, Ansari RH, Schilsky RL, Vokes EE (1998) Phase II trial of 150-minute weekly infusion of gemcitabine in advanced colorectal cancer: minimal activity in colorectal cancer. Invest New Drugs 16: 275-278

Markman M (2002) Second-line treatment of ovarian cancer with singleagent gemcitabine. Semin Oncol 29(1 Suppl 1): 9-10

Mercer SJ, Somers SS, Knight LA, Whitehouse PA, Sharma S, Di Nicolantonio F, Glaysher S, Simon Toh S, Cree IA, for the Portsmouth Upper GI Cancer Multi-Disciplinary Team (2003) Heterogeneity of 
chemosensitivity of oesophageal and gastric carcinoma. Anti-Cancer Drugs 14: $397-403$

Moertel C, Reitemeier R, Hahn R (1968) Mitomycin C therapy in advanced gastrointestinal cancer. JAMA 204: $1045-1048$

Moore DF, Pazdur R, Daugherty K, Tarassoff P, Abbruzzese JL (1992) Phase II study of gemcitabine in advanced colorectal adenocarcinoma. Invest New Drugs 10: $323-325$

Moore GE, Bross DJ, Ausman R, Nadler S, Jones R, Slack N, Rimm AA (1968) Effects of mitomycin C (NSC-26980) in 346 patients with advanced cancer. Cancer Chem Rep 52(6): 675-684

Neale MH, Myatt N, Cree IA, Kurbacher CM, Foss AJ, Hungerford JL, Plowman PN (1999) Combination chemotherapy for choroidal melanoma: ex vivo sensitivity to treosulfan with gemcitabine or cytosine arabinoside. $\mathrm{Br}$ J Cancer 79: $1487-1493$

NICE (2002) Guidance on the use of irinotecan, oxaliplatin and raltitrexed for the treatment of advanced colorectal cancer - Technology Appraisal Guidance No. 33. National Institute for Clinical Excellence: London

Nordic Gastrointestinal Tumour Adjuvant Therapy Group (1992) Expectancy or primary chemotherapy in patients with advanced asymptomatic colorectal cancer: a randomised trial. J Clin Oncol 10(6): 904-911

Peters GJ, Bergman AM, Ruiz van Haperen VW, Veerman G, Kuiper CM, Braakhuis BJ (1995) Interaction between cisplatin and gemcitabine in vitro and in vivo. Semin Oncol 22(4 Suppl 11): $72-79$

Poch G, Reiffenstein RJ, Kock P, Pancheva SN (1995) Uniform characterization of potentiation in simple and complex situations when agents bind to different molecular sites. Can J Physiol Pharmacol 73: $1574-1581$

Price T, Cunningham D, Hickish T, Tait D, Norman A, Ross PJ, Middleton G, Ford HE, Sumpter K (1999) Phase III study of mitomycin-C wth protracted venous infusion $5 \mathrm{FU}$ or circadian timed infusion $5 \mathrm{FU}$ in advanced colorectal cancer. Proc ASCO 1008 (abstract)

Ross P, Nicolson M, Cunningham D, Valle J, Seymour M, Harper P, Price T, Anderson H, Iveson T, Hickish T, Lofts F, Norman A (2002) Prospective randomised trial comparing mitomycin, cisplatin and protracted venous infusion fluorouracil (PVI 5-FU) with epirubicin, cisplatin and PVI 5-FU in advance esophagogastric cancer. J Clin Oncol 20(8): 1996-2004

Ross P, Norman A, Cunningham D, Webb A, Iveson T, Padhani A, Prendiville J, Watson M, Massey A, Popescu R, Oates J (1997) A prospective randomised trial of protracted venous infusion 5-fluorour- acil with or without mitomycin $\mathrm{C}$ in advanced colorectal cancer. Ann Oncol 8: $995-1001$

Russello O, Romanini A, Civalleri D, Rosso R, Nicolin A, Sobrero A (1989) Time-dependent interactions between 5-fluorouracil and mitomycin $\mathrm{C}$ on a human cancer cell line, HCT-8, in vitro. Eur J Cancer Clin Oncol 25: $571-572$

Saltz LB, Cox JV, Blanke C, Rosen LS, Fehrenbacher L, Moore MJ, Maroun JA, Ackland SP, Locker PK, Pirotta N, Elfring GL, Miller LL (2000) Irinotecan plus fluorouracil and leucovorin for metastatic colorectal cancer. Irinotecan Study Group. $N$ Engl J Med 343: 905 - 914

Sandler AB, Nemunatis J, Denham C, von Pawel J, Cormier Y, Gatzemeier U, Mattson K, Manegold Ch, Palmer MC, Gregor A, Nguyen B, Niyikiza C, Einhorn KH (2000) Phase III trial of gemcitabine plus cisplatin versus cisplatin alone in patients with locally advanced or metastatic non-smallcell lung cancer. J Clin Oncol 18: $122-130$

Sartorelli AC, Booth BA (1965) The synergistic anti-neoplastic activity of combinations of mitomycins with either 6-thioguanine or 5-fluourouracil. Cancer Res 25: $1393-1400$

Spanswick VJ, Cummings J, Ritchie AA, Smyth JF (1998) Pharmacological determinants of the antitumour activity of mitomycin C. Biochem Pharm 56: $1497-1503$

Tebbutt NC, Norman A, Cunningham D, Iveson T, Seymour M, Hickish T, Harper P, Maisey N, Mochlinski K, Prior Y, Hill M (2002) A multicentre randomised phase III trial comparing protracted venous infusion (PVI) 5-fluorouracil (5-FU) with PV 5-FU plus mitomycin C in patients with inoperable oesophagogastric cancer. Ann Oncol 13(10): $1568-1575$

van Moorsel CJ, Pinedo HM, Smid K, Comijn EM, Voorn DA, Veerman G, Lakerveld B, Van der Vijgh WJ, Postmus PE, Peters GJ (2000) Scheduledependent pharmacodynamic effects of gemcitabine and cisplatin in mice bearing Lewis lung murine non-small cell lung tumours. Eur J Cancer 83(8): 2420-2429

van Moorsel CJ, Veerman G, Bergman AM, Guechev A, Vermorken JB, Postmus PE, Peters GJ (1997) Combination chemotherapy studies with gemcitabine. Semin Oncol 24(2 Suppl 7): S7-17-S7-23

Whitehouse PA, Knight LA, Di Nicolantonio F, Mercer SJ, Sharma S, Cree IA (2003) Heterogeneity of chemosensitivity of colorectal adenocarcinoma determined by a modified ex vivo ATP-tumour chemosensitivity assay (ATP-TCA). Anticancer Drugs 14: 369-375 